\title{
Preparation and evaluation of mucoadhesive buccal tablet for oral infection disease
}

\author{
Surajj Sarode', S. D. Barhate ${ }^{1}$, P. R. Patil ${ }^{2}$, Md. Ragib Usman ${ }^{3}$, A. R. Bendale ${ }^{4}$ \\ 'Department of Pharmaceutics, SSJIPER College of Pharmacy, Jamner, Maharashtra, India, ${ }^{2}$ Department of Pharmacology, Arunamai College of Pharmacy, Mamurabad, \\ Maharashtra, India, ${ }^{3}$ Department of Pharmacognosy, Smt. S. S. Patil College of Phamacy, Chopda, Maharashtra, India, ${ }^{4}$ Department of Pharmaceutics, Sandip College of \\ Pharmacy, Nashik, Maharashtra, India
}

\begin{abstract}
In recent years, significant interest has been shown in the development of novel bioadhesive dosage forms for mucosal delivery of drugs. A drug administered through the buccal mucosa enters directly to the systemic circulation, thereby minimizing the first-pass hepatic metabolism and adverse gastrointestinal effect. The objective of the project was to develop a stable and robust formulation of buccal tablet of the selected antifungal drug miconazole nitrate for the treatment of oral candidiasis. Oral candidiasis is an opportunistic infection of the mouth, highly prevalent in a specific group of patients including AIDS patients. Without treatment, the lesion may spread to the esophagus, causing invasive esophageal candidiasis, which is categorized as an AIDS-defining illness. Miconazole nitrate has a broad-spectrum of activity against most pathogenic fungi and Gram-positive bacteria. The drug has poor aqueous solubility. It has the potential to be used in the treatment of all forms of both mucosal and systemic candidiasis. The result of the project would

provide a process that would provide stable formulation of buccal tablet. In this project, buccal tablet was prepared by direct compression. Among different trials with direct compression, the trial batch showed satisfactory in vitro drug release profile as compared to that of innovator for sustained release formulation.
\end{abstract}

Correspondence:

Dr. Surajj Sarode,

Department of Pharmaceutics, SSJIPER College of

Pharmacy, Jamner,

Maharashtra, India. Phone: +91-7397950974.

E-mail:drsurajjsarode@gmail.com
Keywords: Miconazole nitrate, mucoadhesion, mucosal drug delivery, oral candidiasis

\section{Introduction}

\section{Buccal drug delivery system}

Among the various routes of drug delivery, the peroral has been one of the most convenient and widely accepted routes of delivery for most therapeutic agents. However, peroral administration of drugs has disadvantages, such as hepatic first-pass metabolism and enzymatic degradation within the gastrointestinal tract. These disadvantages may limit or prevent the oral administration of certain classes of drugs, especially peptides and proteins. Transmucosal routes of drug delivery offer distinct advantages over peroral administration for systemic drug delivery. These advantages include possible bypass of first-pass effect and avoidance of presystemic elimination within the gastrointestinal

\section{Access this article online}

Website: http://www.jpbs-online.com

E-ISSN: $2321-0125$

DOI: $10.31555 / \mathrm{jpbs} / 2017 / 5 / 4 / 38-43$

How to cite this article: Sarode $S$, Patil PR, Barhate SD, Usman MR, Bendale AR. Preparation and evaluation of mucoadhesive buccal tablet for oral infection disease. J Pharm BioSci 2017;5(4):38-43.

Source of Support: Nil, Conflict of Interest: None declared. tract (Bruschi et al., 2005). The mucosal layer lines a number of regions of the gastrointestinal tract, the airways, the ear, nose, and the eye, and hence, the mucoadhesive drug delivery system includes the following.

1. Buccal delivery system

2. Sublingual delivery system

3. Vaginal delivery system

4. Rectal delivery system

5. Nasal delivery system

6. Ocular delivery system.

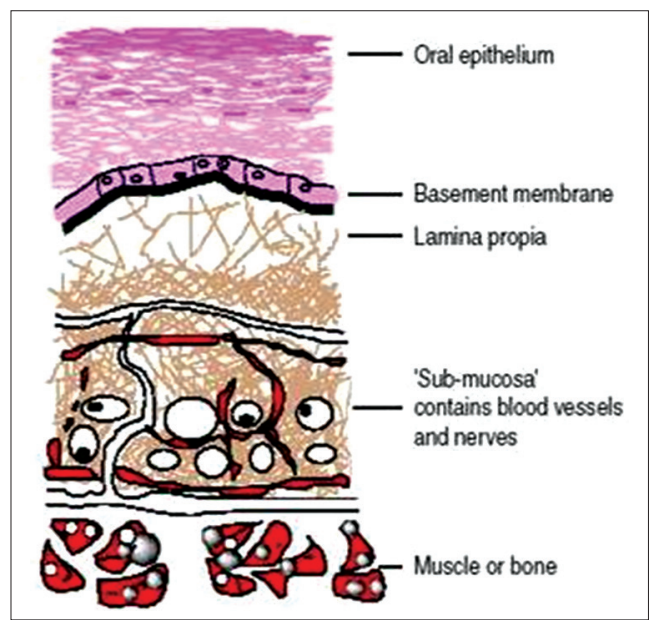


Drugs administered through the oral mucosa gain access to the systemic circulation through a network of arteries and capillaries. The major artery supplying the blood to the oral cavity is the external carotid artery. The venous backflow goes through branches of capillaries and veins and is finally taken up by the jugular vein. The gingiva and the hard palate are lined with a masticatory mucosa, where the epithelium has a cornified surface containing keratin. Keratin is found in the superficial cells of the epithelium which become flattened and virtually devoid of organelles. Keratinized tissue may be subdivided into or tho-keratinized and para-keratinized or non-keratinized. In orthokeratinized cells, a predominant granular layer is present, which is not present in parakeratinized tissue cells. The keratinized epithelia contain neutral lipids such as ceramides and acyl ceramides which have been associated with the barrier function. These epithelia are relatively impermeable to water. In contrast, non-keratinized epithelia such as the floor of the mouth and the buccal epithelia do not contain acylceramides and possess only small amounts of ceramide. They contain few neutral but polar lipids, particularly cholesterol sulfate and glucosylceramides..$^{1-3}$

\section{Factors affecting mucoadhesion ${ }^{4-6}$}

\section{Polymer-related factors}

Molecular weight

The bioadhesive strength of a polymer increases with molecular weights above $1,00,000$. The fact that bioadhesiveness improves with increasing molecular weight for a linear polymer implies two things: (1) Interpenetration is more critical for low molecular weight polymer to be a good bioadhesive and (2) entanglement is important for high molecular weight polymers.

\section{Concentration of active polymer}

When the concentration of the polymer is too low, the number of penetrating polymer chains per unit volume of the mucus is small, and the interaction between polymer and mucus is unstable.

\section{Flexibility of polymer chains}

Chain flexibility is critical for interpenetration and entanglement. As water soluble-polymers become cross-linked, mobility of an individual polymer chain decreases and thus the effective length of the chain that can penetrate into the mucus layer decreases which reduces bioadhesive strength.

\section{Charge}

Nonionic polymers appear to undergo a smaller degree of adhesion compared to anionic polymers. Some cationic polymers are likely to demonstrate superior mucoadhesive properties, especially in a neutral or slightly alkaline medium.

\section{Cross-linking density}

The average pore size, the number average molecular weight of the cross-linked polymers, and the density of cross-linking are three important and interrelated structural parameters of a polymer network.

\section{Swelling}

Polymer swelling permits a mechanical entanglement by exposing the bioadhesive sites for hydrogen bonding and/or electrostatic interaction between the polymer and the mucous network.

\section{Environment-related factors}

$\mathrm{pH}$ of polymer-substrate interface

$\mathrm{pH}$ can influence the formal charge on the surface of the mucus as well as certain ionizable bioadhesive polymers.

\section{Physiological factors}

\section{Disease state}

The physiochemical properties of the mucus are known to change during disease conditions such as the common cold, gastric ulcers, ulcerative colitis, cystic fibrosis, bacterial, and fungal infections of female reproductive tract and inflammatory conditions of the eye.

\section{Mucin turnover}

The mucin turnover is expected to limit the residence time of the mucoadhesives on the mucus layer. Second, mucin turnover results in substantial amounts of soluble mucin molecules.

\section{Materials and Methods}

\section{Materials}

The following drug, polymers, and chemicals were used for the formulation and evaluation of tablets.

List of solvents and chemical:

- $\quad$ Distilled water

- Methanol

- Acetone

- Concentrated hydrochloric acid

- Ammonium acetate

- Acetonitrile.

(All the chemicals used were of analytical reagent grade) (Tables 1 and 2).

\section{Results and Discussion}

\section{Preformulation study $y^{7,8}$}

\section{Identification of drug}

Identification of drug was carried out by melting point determination, infrared spectroscopy, and differential scanning calorimetry (DSC).

\section{Melting point method}

Melting point method is prime confirmation of drug. In this method, temperature was noted at which point sample start melt to finish. The melting point of MCN was measured and

Table 1: List of materials and chemicals used with their source

\begin{tabular}{ll} 
Materials & Manufacturer (supplier) \\
\hline MCN U.S.P. & Merck Pharma, Goa, India \\
HPMC K4M & Doshion Pharma-Polymer Division, Ahmedabad, India \\
NaCMC & Doshion Pharma-Polymer Division, Ahmedabad, India \\
Sod. alginate & Doshion Pharma-Polymer Division, Ahmedabad, India \\
Carbomer & Corel Pharmaceuticals, Ahmedabad, India \\
Agar & Marine Chemical, Kerala, India \\
\hline
\end{tabular}


found to be in the range of $186-188^{\circ} \mathrm{C}$. It was confirmed with the reported melting point of $\mathrm{MCN}$, i.e., $182-186^{\circ} \mathrm{C}$ (Clark's analysis, Vol. 2, 1282).

\section{Fourier transform infrared (FTIR) spectroscopy}

IR spectrum of the drug was measured in the solid state as potassium bromide dispersion. The bands $\left(\mathrm{cm}^{-1}\right)$ have been assigned. An FTIR spectrum of miconazole nitrate was obtained using an FTIR spectrometer-430 (8400S, Shimadzu, Japan).

Melting point determination by DSC

The melting point of drug was determined using DSC. Thermograms for MCN were obtained using DSC (Cyrus-DSCWipro GE DX-300, Perkin Elmer, USA).

\section{Drug-excipient interaction study ${ }^{9}$}

The drug-excipients interaction study was carried out by using FTIR and DSC.

\section{FTIR spectroscopy}

Infrared spectroscopy is used to predict possible drug-excipients interaction study. IR spectrum of drug was measured in the solid state as potassium bromide dispersion. The drug, polymers, and physical mixture were filled in pre-washed and dried ampoules and sealed with aluminum paper. The sealed ampoules were kept at $37 \pm 0.5^{\circ} \mathrm{C}$ for 28 days in stability chamber (TH 90 G, Thermolab, Thane, India) (Table 3).

Table 2: List of equipments used with their make

\begin{tabular}{ll} 
Equipment & Manufacturers \\
Weighing balance & PG 403-S Mettler Toledo, Columbus, OH \\
pH meter & $\begin{array}{l}\text { Cyberscan pH 1500, Thermo Electron } \\
\text { Corporation, Waltham, MA, USA }\end{array}$ \\
Tap density tester (USP-II) & ETD -1020, Electrolab, Mumbai, India \\
27 station tablet machine & CMB3-D27 Cadmach, Ahmedabad, India \\
Hardness tester & Dr. Schleunizer Pharmaton (5 y), Manchester, USA \\
Friability tester & EF-1W Electrolab, Mumbai, India \\
Vernier caliper scale & Mitutoyo, Aurora, USA \\
Malvern particle size analyzer & Morphology G3, Malvern, Worcestershire, UK \\
Stability chamber & TH 90 G, Thermolab, Thane, India \\
Mechanical shaker & RO-123R, Remi International, Mumbai, India \\
Dissolution test apparatus & TDT 08L Plus, Electrolab TDT 08L Plus \\
HPLC & LC 2010, SHIMADZU, Japan \\
DSC & Cyrus-DSC Wipro GE DX-300, Perkin Elmer, \\
& Massachusetts, USA \\
FTIR & 8400S, SHIMADZU, Japan \\
Ultraviolet spectrophotometer & 1800, SHIMADZU, Japan \\
\hline
\end{tabular}

HPLC: High-performance liquid chromatography, DSC: Differential scanning calorimetry, FTIR: Fourier transform infrared

\section{$\operatorname{DSC}^{10,11}$}

Drug, polymers, and physical mixtures were filled in the pre-washed and dried ampoules and sealed. The sealed ampoules were kept at $37 \pm 0.5^{\circ} \mathrm{C}$ for 28 days in stability chamber (Thermolab, Thane, India). At the end of 28 days, ampoules were removed from stability chamber and proceed for interaction study.

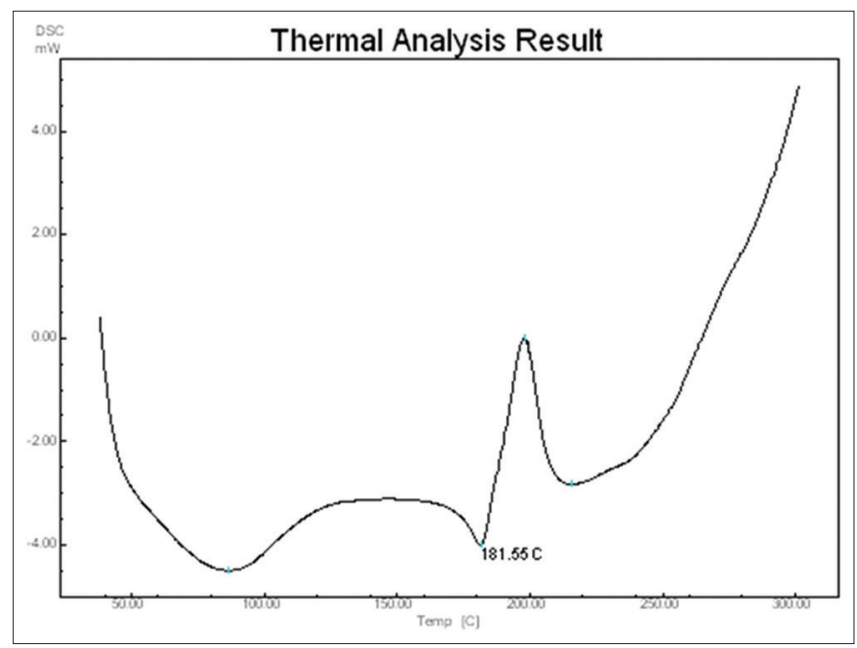

Analysis of drug ${ }^{12,13}$

Solubility study of MCN in different solvents

Drug solubility was determined by preparing saturated drug solutions in distilled water and buffer medium, maintained at $37 \pm 0.5^{\circ} \mathrm{C}$ in a water bath, and continually shaken using mechanical shaker (RO123R, Remi Instruments, Mumbai, India) up to 24 h (Table 4).

Standard calibration curve of drug

Standard stock solution

Accurately weighed $10 \mathrm{mg}$ of MCN USP was taken and transferred in $100 \mathrm{ml}$ volumetric flask. Diluent $(0.2 \mathrm{M}$ ammonium acetate buffer:acetonitrile:methanol 20:30:50) was added to dilute the solution up to $100 \mathrm{ml}$.

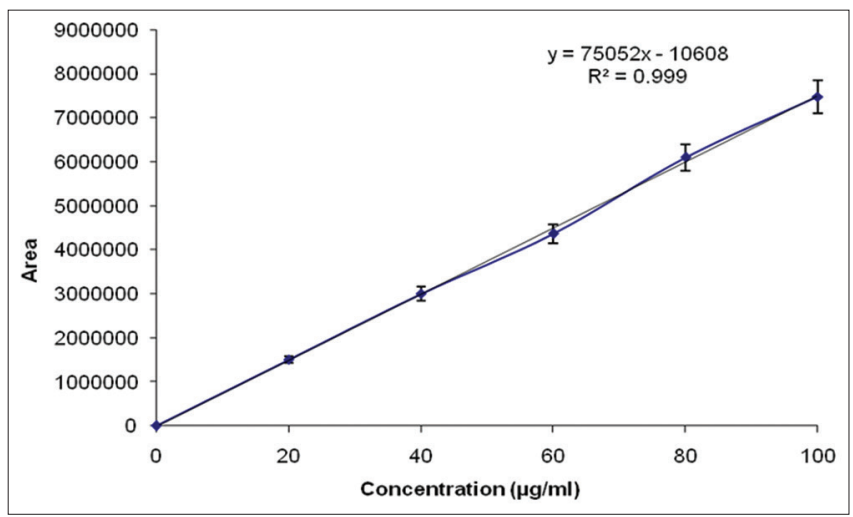

Table 3: FTIR spectra

\begin{tabular}{|c|c|c|c|c|}
\hline Polymer & Drug peak & Polymer peak & Drug ${ }^{+}$polymer peak & Interaction \\
\hline HPMC & $812.92,827.49,1038.67,1319.50$ & $852.56,944.19$ & $812.92,827.49,858.35,949.01,1038.67,1319.50$ & No \\
\hline $\mathrm{NaCMC}$ & $812.92,827.49,1038.67,1319.50$ & $1327.07,1585.18$ & $812.92,827.49,1038.67,1319.50,1330.93,1588.85$ & No \\
\hline Sod. Alginate & $812.92,827.49,1038.67,1319.50$ & $637.96,855.46,1036.92,1470.27$ & $637.49,812.92,827.49,859.32,1039.67,1319.50,1472.70$ & No \\
\hline Carbomer & $812.92,827.49,1038.67,1319.50$ & $1168.90,1216.09$ & $812.92,827.49,1038.67,1168.90,1216.16,1319.50$ & No \\
\hline
\end{tabular}




\section{Formulation of buccal tablet ${ }^{14,15}$}

Mucoadhesive buccal tablets were prepared by a direct compression procedure (Table 5).

\section{Evaluation of pre-compression parameters ${ }^{16,17}$}

Drug and polymers were characterized for their physical properties such as particle size distribution, angle of repose, density, compressibility, and Hausner's ratio. Results are shown in Table 6.

Particle size determination ${ }^{18,19}$

For many active substances, particle size has an impact on powder flow; content uniformity, and drug dissolution. To assure consistent product quality, the particle size of the API has been characterized (By Malvern mastersizer, Dry method). From the results obtained, the limits will be derived which will be routinely applied by the API manufacturer during analysis of drug (Table 7).

Angle of repose, density, compressibility index,

\section{Hausner's ratio}

Pre-compression parameters of tablets powder blends $\mathrm{s}^{20,21}$

The tablet of optimized formula powder blend shows good flow property (angle of repose more than 30 and $<35$ ). Results are shown in Table 8.

\section{Post compression parameters}

Prepared tablets were evaluated for post compression parameters (Tables 9 and 10).

Table 4: Solubility in different solvents

\begin{tabular}{lc} 
Solvent/media & Solubility $\%$ \\
Water & $0.03 \pm 0.01$ \\
$0.1 \mathrm{~N} \mathrm{HCL}$ & $97.33 \pm 0.58$ \\
$0.2 \mathrm{M}$ ammonium acetate buffer & $34.5 \pm 0.46$ \\
\hline
\end{tabular}

Table 5: Formulation composition of prepared batches

\begin{tabular}{lcccccccccc} 
Composition $(\mathbf{m g})$ & \multicolumn{10}{c}{ Batch code } \\
\cline { 2 - 11 } & F1 & F2 & F3 & F4 & F5 & F6 & F7 & F8 & F9 & F10 \\
MCN & 10 & 10 & 10 & 10 & 10 & 10 & 10 & 10 & 10 & 10 \\
HPMC & 35 & 30 & 30 & 20 & - & 10 & 15 & 25 & 10 & 60 \\
NaCMC & 50 & - & 20 & 35 & 40 & 45 & 50 & 55 & 25 & 15 \\
Sod. alginate & - & 50 & 35 & 25 & 45 & 30 & 20 & 5 & 50 & 10 \\
Carbomer & 5 & 10 & 5 & 10 & 5 & 5 & 5 & 5 & 5 & 5 \\
Total & 100 & 100 & 100 & 100 & 100 & 100 & 100 & 100 & 100 & 100 \\
\hline
\end{tabular}

\section{Swelling index}

Table 11 shows swelling index of miconazole nitrate buccal tablet.

\section{Ex vivo bioadhesion study}

Table 12 shows ex vivo bioadhesion study of prepared miconazole nitrate buccal tablet.

\section{In vitro drug release profile}
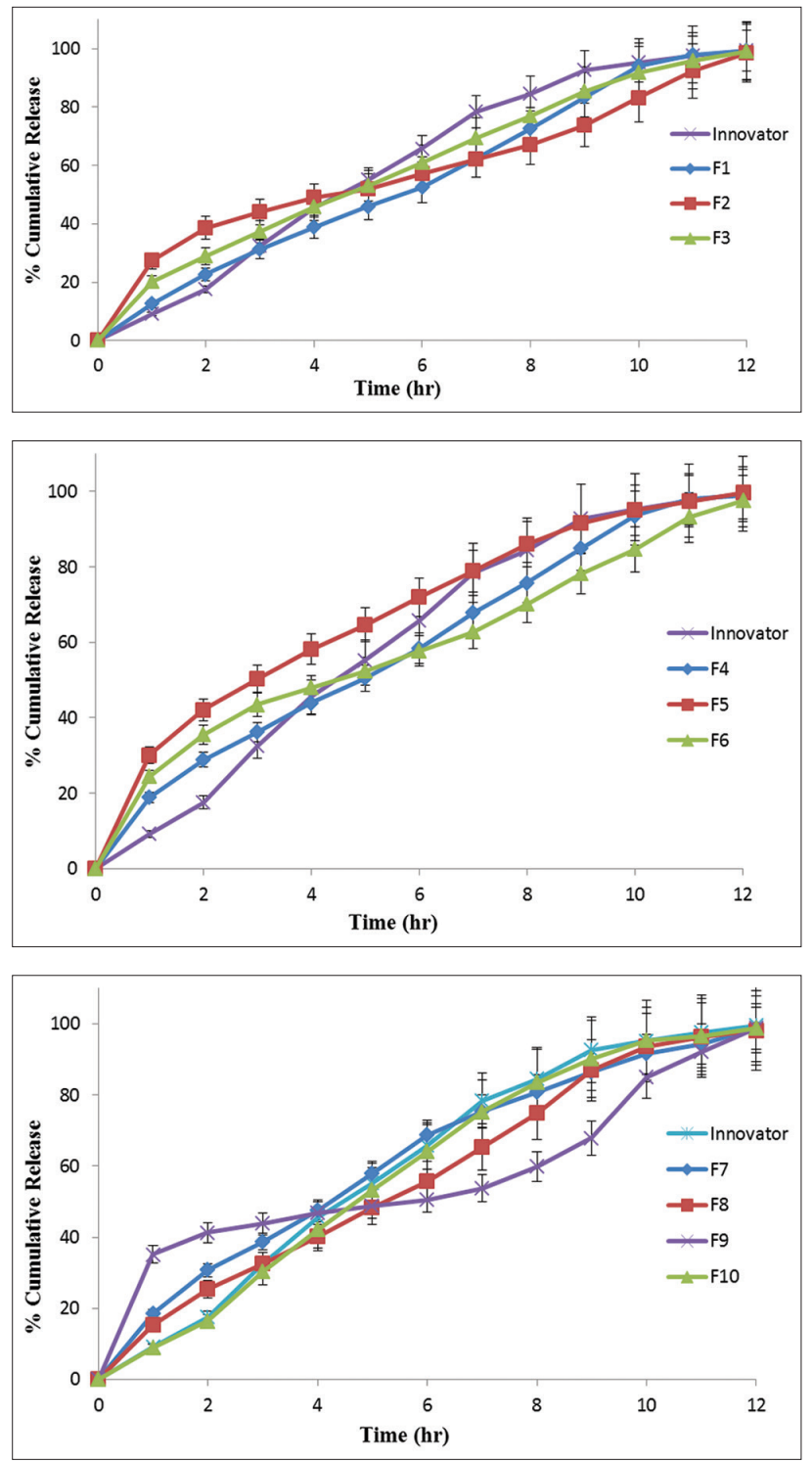

Table 6: Physical parameters of drug and polymers

\begin{tabular}{lccccc} 
Ingredients & \multicolumn{5}{c}{ Parameter } \\
\cline { 2 - 6 } & Angle of repose $(\boldsymbol{\theta})$ & Bulk density $\left(\mathbf{g} / \mathbf{c m}^{3}\right)$ & Tapped density $\left(\mathbf{g} / \mathbf{c m}^{3}\right)$ & Compressibility index (\%) & Hausner's ratio $(\mathbf{H R})$ \\
Miconazole nitrate & $33.05 \pm 0.15$ & $0.21 \pm 0.06$ & $0.53 \pm 0.10$ & $36.04 \pm 0.41$ & $1.34 \pm 0.1$ \\
HPMC & $32.91 \pm 0.79$ & $0.360 \pm 0.05$ & $0.42 \pm 0.03$ & $23.35 \pm 0.61$ & $1.2 \pm 0.03$ \\
NaCMC & $34.22 \pm 1.5$ & $0.30 \pm 0.15$ & $0.43 \pm 0.015$ & $30.23 \pm 1.45$ & $1.43 \pm 0.34$ \\
Sod. alginate & $26.24 \pm 0.15$ & $0.36 \pm 0.3$ & $0.46 \pm 0.04$ & $21.67 \pm 0.67$ & $1.29 \pm 0.03$ \\
Carbomer & $33.32 \pm 1.7$ & $0.25 \pm 0.01$ & $0.28 \pm 0.028$ & $10.75 \pm 0.14$ & $1.12 \pm 0.34$ \\
\hline
\end{tabular}

All values are mean $\pm S D, n=3$. SD: Standard deviation 
Table 7: Particle size distribution of miconazole nitrate

\section{Particle size distribution}

$\mathrm{D}(\mathrm{v}, 0.1)$

$\mathrm{D}(\mathrm{v}, 0.5)$

$\mathrm{D}(\mathrm{v}, 0.9)$

Table 8: Pre-compression parameters of tablets powder blend

\section{Ingredients}

$\mu \mathrm{m}$

1.92

6.46

28.81

\section{Conclusion}

1. In the pre-formulation study (compatibility study), compatibility of the excipients used in the formulation with drug was done by FTIR and DSC. Results of the compatibility study reveal

\begin{tabular}{|c|c|c|c|c|c|}
\hline $\begin{array}{l}\text { Optimized formula } \\
\text { powder blend }\end{array}$ & $31.66 \pm 0.12$ & $0.36 \pm 0.014$ & $0.75 \pm 0.041$ & $25.47 \pm 0.69$ & $1.17 \pm 0.065$ \\
\hline
\end{tabular}

Table 9: Thickness, diameter, hardness, and weight variation of prepared buccal tablets

\begin{tabular}{lcccc} 
Formulation code & \multicolumn{3}{c}{ Parameter } \\
\cline { 2 - 5 } & Thickness $(\mathbf{m m})$ & Diameter $(\mathbf{m m})$ & Hardness $\left(\mathbf{k g} / \mathbf{c m}^{2}\right)$ & Weight variation $(\mathbf{m g})$ \\
F1 & $2.60 \pm 0.19$ & $6.54 \pm 0.02$ & $4.7 \pm 0.04$ & $105.7 \pm 0.4$ \\
F2 & $2.65 \pm 0.08$ & $6.52 \pm 0.06$ & $4.4 \pm 0.11$ & $100.7 \pm 0.13$ \\
F3 & $2.60 \pm 0.14$ & $6.64 \pm 0.04$ & $4.4 \pm 0.04$ & $104.0 \pm 0.36$ \\
F4 & $2.71 \pm 0.2$ & $6.68 \pm 0.07$ & $3.7 \pm 0.11$ & $105 \pm 0.19$ \\
F5 & $2.81 \pm 0.05$ & $6.54 \pm 0.03$ & $4.0 \pm 0.05$ & $106.4 \pm 0.64$ \\
F6 & $2.74 \pm 0.05$ & $6.53 \pm 0.06$ & $4.4 \pm 0.05$ & $105.9 \pm 0.18$ \\
F7 & $2.81 \pm 0.18$ & $6.54 \pm 0.07$ & $5.4 \pm 0.15$ & $100.7 \pm 0.52$ \\
F8 & $2.65 \pm 0.18$ & $6.54 \pm 0.08$ & $3.7 \pm 0.18$ & $101.3 \pm 0.58$ \\
F9 & $2.62 \pm 0.19$ & $6.50 \pm 0.07$ & $4.5 \pm 0.09$ & $100.7 \pm 0.67$ \\
F10 & $2.73 \pm 0.12$ & $6.58 \pm 0.05$ & $4.7 \pm 0.15$ & $100.2 \pm 0.47$ \\
\hline
\end{tabular}

All values are expressed as mean $\pm \mathrm{SD}, \mathrm{n}=3$. SD: Standard deviation

Table 10: Friability, drug content, surface $\mathrm{pH}$ of prepared buccal tablet

\begin{tabular}{lccc} 
Formulation code & \multicolumn{3}{c}{ Parameter } \\
\cline { 2 - 4 } & Friability (\%) & Drug content (\%) & Surface pH \\
F1 & $0.21 \pm 0.04$ & $99.35 \pm 0.63$ & $6.50 \pm 0.01$ \\
F2 & $0.47 \pm 0.01$ & $97.10 \pm 0.16$ & $5.98 \pm 0.02$ \\
F3 & $0.48 \pm 0.02$ & $99.34 \pm 0.23$ & $6.44 \pm 0.10$ \\
F4 & $0.44 \pm 0.05$ & $98.85 \pm 0.62$ & $6.42 \pm 0.03$ \\
F5 & $0.05 \pm 0.01$ & $96.40 \pm 1.21$ & $6.94 \pm 0.12$ \\
F6 & $0.06 \pm 0.02$ & $99.03 \pm 0.49$ & $6.40 \pm 0.09$ \\
F7 & $0.02 \pm 0.06$ & $98.56 \pm 0.52$ & $6.13 \pm 0.07$ \\
F8 & $0.04 \pm 0.03$ & $98.05 \pm 0.36$ & $6.13 \pm 0.04$ \\
F9 & $0.27 \pm 0.02$ & $100.02 \pm 0.46$ & $6.41 \pm 0.30$ \\
F10 & $0.24 \pm 0.02$ & $100.02 \pm 0.45$ & $6.45 \pm 0.02$ \\
\hline
\end{tabular}

Table 11: Swelling index of miconazole nitrate buccal tablet

\begin{tabular}{lccccc} 
Formulation & \multicolumn{4}{c}{ Swelling index (h) } \\
\cline { 2 - 6 } & $\mathbf{1}$ & $\mathbf{2}$ & $\mathbf{4}$ & $\mathbf{8}$ \\
F1 & $78.84 \pm 0.04$ & $87.47 \pm 0.02$ & $89.14 \pm 0.03$ & $92.19 \pm 0.03$ & $\mathbf{1 2}$ \\
F2 & $60.89 \pm 0.04$ & $69.36 \pm 0.03$ & $73.47 \pm 0.13$ & $77.74 \pm 0.07$ & $76.88 \pm 0.08$ \\
F3 & $72.48 \pm 0.07$ & $81.90 \pm 0.05$ & $84.43 \pm 0.09$ & $87.43 \pm 0.03$ & $85.99 \pm 0.07$ \\
F4 & $50.57 \pm 0.10$ & $62.39 \pm 0.07$ & $68.00 \pm 0.05$ & $75.08 \pm 0.07$ \\
F5 & $61.05 \pm 0.08$ & $6913 \pm 0.12$ & $74.12 \pm 0.05$ & $79.83 \pm 0.04$ & $73.21 \pm 0.05$ \\
F6 & $57.21 \pm 0.07$ & $66.76 \pm 0.09$ & $70.20 \pm 0.05$ & $76.08 \pm 0.04$ & $78.20 \pm 0.04$ \\
F7 & $47.50 \pm 0.08$ & $58.13 \pm 0.14$ & $65.08 \pm 0.13$ & $71.70 \pm 0.04$ & $74.43 \pm 0.03$ \\
F8 & $70.49 \pm 0.02$ & $79.75 \pm 0.01$ & $84.54 \pm 0.01$ & $87.92 \pm 0.01$ & $70.00 \pm 0.08$ \\
F9 & $44.31 \pm 0.08$ & $55.21 \pm 0.07$ & $64.65 \pm 0.05$ & $69.30 \pm 0.09$ & $86.12 \pm 0.01$ \\
F10 & $84.52 \pm 0.02$ & $92.98 \pm 0.04$ & $93.40 \pm 0.08$ & $93.97 \pm 0.05$ \\
\hline
\end{tabular}


Table 12: Ex vivo bioadhesion study of prepared miconazole nitrate buccal tablet

$13.4 \pm 0.20$
$13.7 \pm 0.40$
$13.9 \pm 0.32$
$14.5 \pm 0.23$
$14.4 \pm 0.31$
$13.8 \pm 0.10$
$13.5 \pm 0.62$
$13.8 \pm 0.15$
$13.8 \pm 0.44$
$14.7 \pm 0.20$

that the drug was compatible with all excipients used in the formulation.

2. Here, direct compression strategy found satisfactory for all formulation. Hence, direct compression strategy was adopted.

3. Various physicochemical parameters such as content uniformity, thickness, weight variation, bioadhesive strength, surface $\mathrm{pH}$, swelling study, and matrix erosion were evaluated.

4. Among different trials with direct compression, trial F10 had satisfactory in-vitro dissolution profile in comparison to the innovator. Hence, these batches tablets were selected for the preparation of tablets.

5. Stability study was carried out for the optimized formulation at $40^{\circ} \mathrm{C} / 75 \% \mathrm{RH}$ for 3 months. The result shows no significant change in physical and chemical parameter of the tablet; hence, the formulation was found to be stable.

\section{References}

1. Moffat AC, Osselton MD, Widdop B. Clarke's Analysis of Drugs and Poison. $3^{\text {rd }}$ ed., Vol. 2. London: Pharmaceutical Press; 2004. p. 1282-3.

2. Nafee NA, Ismail FA, Boraie NA, Mortada LM. Mucoadhesive buccal patches of miconazole nitrate: In vitro/in vivo performance and effect of ageing. Int J Pharm 2003;264:1-14.

3. Nicolazzo JA, Reed BL, Finnin BC. Buccal penetration enhancers - How do they really work? J Control Release 2005;105:1-15.

4. Nafee NA, Ismail FA, Boraie NA, Mortada LM. Mucoadhesive delivery systems. II. Formulation and In-vitro/In-vivo evaluation of buccal mucoadhesive tablets containing water-soluble drugs. Drug Dev Ind Pharm 2004;30:995-1004.

5. Nittayananta W, DeRouen TA, Arirachakaran P, Laothumthut T, Pangsomboon K, Petsantad S, et al. A randomized clinical trial of chlorhexidine in the maintenance of oral candidiasis-free period in HIV infection. Oral Dis 2008;14:665-70.

6. Park CR, Munday DL. Development and evaluation of a biphasic buccal adhesive tablet for nicotine replacement therapy. Int J Pharm 2002;237:215-26.
7. Patel VM, Prajapati BG, Patel HV, Patel KM. Mucoadhesive bilayer tablets of propranolol hydrochloride. AAPS PharmSciTech 2007;8:E77.

8. Perioli L, Ambrogi V, Angelici F, Ricci M, Giovagnoli S, Capuccella M, et al. Development of mucoadhesive patches for buccal administration of ibuprofen. J Control Release 2004;99:73-82.

9. Smart JD. The basics and underlying mechanisms of mucoadhesion. Adv Drug Deliv Rev 2005;57:1556-68.

10. Shojaei AH. Buccal mucosa as a route for systemic drug delivery: A review. J Pharm Pharm Sci 1998;1:15-30.

11. Simonetti N, Simonetti G, Strippoli V, Callari A, Tecca M. Susceptibility assays of Cundida tropicalis to miconazole. J Micro Method 1997;30:221-9.

12. Patton LL, Bonito AJ, Shugars DA. A systematic review of the effectiveness of antifungal drugs for the prevention and treatment of oropharyngeal candidiasis in HIV-positive patients. Oral Surg Oral Med Oral Pathol Oral Radiol Endod 2001;92:170-9.

13. Ponchel G. Formulation of oral mucosal drug delivery systems for the systemic delivery of bioactive materials. Adv Drug Deliv Rev 1994;13:75-87.

14. Rambali B, Baert L, Jans E, Massart DL. Influence of the roll compactor parameter settings and the compression pressure on the buccal bio-adhesive tablet properties. Int J Pharm 2001;220:129-40.

15. Rathbone MJ, Drummond BK, Tucker IG. The oral cavity as a site for systemic drug delivery. Adv Drug Deliv Rev 1994;13:1-22.

16. Samaranayake LP, Ferguson MM. Delivery of antifungal agents to the oral cavity. Adv Drug Deliv Rev 1994;13:161-79.

17. Scholz OA, Wolff A, Schumacher A, Giannola LI, Campisi G, Ciach T, et al. Drug delivery from the oral cavity: Focus on a novel mechatronic delivery device. Drug Discov Today 2008;13:247-53.

18. Rossi S, Sandri G, Caramella CM. Buccal drug delivery: A challenge already won? Drug Discov Today Technol 2005;2:59-65.

19. Samaranayake LP, Cheung LK, Samaranayake YH. Candidiasis and other fungal disease of the mouth. Dermato Ther 2002;15:251-69.

20. Rathbone MJ, Hadgraft J. Absorption of drugs from the human oral cavity. Int J Pharm 1991;74:9-24.

21. Spiegeleer BD, Vooren LV, Voorspoels J, Thoné D, Rosier J. Dissolution stability and IVIVC investigation of a buccal tablet. Anal Chim Acta 001;446:345-51. 